\title{
Esophageal Perforation after Thoracic Vertebral Fracture in an Ankylosed Spine: Case Report and Review of the Literature
}

\author{
Johanne Summers ${ }^{1^{*}}$, Craig Timms ${ }^{1}$ and Tony Goldschlagera ${ }^{2}$ \\ ${ }^{1}$ Department of Neurosurgery, Monash Medical Centre, 3168 Victoria, Australia \\ ${ }^{2}$ Department of Surgery, Monash University, 3800 Victoria, Australia
}

"Corresponding author: Dr. Johanne Summers, Department of Neurosurgery, Monash Medical Centre, 3168 Victoria, Australia, Tel: (+61) 402579639; Fax: (+61) 3 95926962; E-mail: johannesummers@gmail.com

Received date: 9 March 2014, Accepted date: 28 April 2014, Published date: 9 May 2014

Copyright: (C) 2014 Summers $\mathrm{J}$ et al. This is an open-access article distributed under the terms of the Creative Commons Attribution License, which permits unrestricted use, distribution, and reproduction in any medium, provided the original author(s) and source are credited.

\begin{abstract}
We present the case of a 74 year-old male with delayed diagnosis of post-traumatic thoracic esophageal perforation that occurred secondary to thoracic vertebral fracture in an ankylosed spine. The injury resulted after a fall from chair secondary to an unconscious collapse due to Ventricular Fibrillation (VF). At 8 days after the injury, the patient was diagnosed with esophageal perforation, secondary to fourth thoracic vertebral fracture without neurological deficit. The esophageal laceration was complicated by sepsis with bacteremia, pleural empyema and mediastinal abscess. Non-surgical management for the esophageal perforation, chest complications and thoracic spine fracture resulted in complete recovery. A case report and review of the literature is presented. We report the first case of post-traumatic thoracic esophageal perforation secondary to thoracic T4 vertebral fracture, in a patient with an ankylosed spine that survived neurologically intact after successful conservative management.
\end{abstract}

Keywords: Esophageal Perforation; Thoracic Esophageal Injuries; Thoracic Vertebral Fracture; Ankylosed Spine; Conservative Management.

\section{Introduction}

Esophageal perforation is a life threatening injury, with serious complications such as sepsis and mediastinitis, and mortality rates $18 \%$ to $48 \%$ [1-6]. Mortality rates greater than $50 \%$ are reported with delayed diagnosis and treatment after 24 hours [7-9]. Prevention of serious complications revolves around early diagnosis and treatment $[4,5]$. The causes of esophageal injuries include iatrogenic, penetrating $(20-25 \%)$ and blunt trauma $(<10 \%)$. Blunt spinal injury as a cause of esophageal perforation is uncommon, and most of the reported cases are due to cervical spine pathology [10-14]. Thoracic spinal fracture resulting in thoracic esophageal perforation is extremely rare, with an incidence of less than $0.2 \%$ [15] and there are only a few reported cases in the literature [7,16-20]. It can occur when thoracic vertebral fracture causes posterior esophageal wall laceration and typically results in death or severe morbidity $[1-3,6,8,21,22]$. A case report and review of the literature is presented. We report the first case of posttraumatic thoracic esophageal perforation secondary to thoracic T4 vertebral fracture after a low velocity fall, in a patient with an ankylosed spine that survived neurologically intact, successfully treated with conservative non-surgical management.

\section{Case Report}

A 74 year-old man, independent from home, was admitted to our hospital after a fall from a chair onto his back, following an episode of VF resulting in an unconscious collapse. After appropriate Automatic Internal Cardiac Defibrillator (AICD) discharge for VF (defibrillator activated, shocked back to paced rhythm), the patient awoke complaining of central chest pain radiating to his back. On arrival of the ambulance service, the patient had a Glasgow Comma Score of 15 and stable hemodynamics, he was neurologically intact and afebrile. On admission to the hospital emergency department, the patient was febrile at $40^{\circ} \mathrm{C}$, but remained stable without neurologic deficit, denied chest or spine tenderness, and there were no symptoms or signs indicating spinal cord compromise. The patient's past medical history consisted of atrial fibrillation on warfarin, dilated cardiomyopathy with an AICD, osteoarthritis, ankylosing spondylitis, renal stent, hypertension, gout, peripheral vascular disease, glaucoma and a past smoking history.

Management and investigation were instigated for the initial diagnosis of unconscious collapse associated with the VF event, which was presumed secondary to sepsis. Initial thoracic spine imaging was not performed. The patient continued to have high fevers with chills and rigors. Blood cultures were positive for staph hominis, strep mitus, and strep milleri bacteremia, treated with intravenous antibiotics, as directed by the infectious diseases unit. The initial source of the sepsis was presumed urinary tract source, as the patient had a complicated renal stent insertion one month prior to admission. From the time of injury the patient complained of chest pain radiating to the interscapular region, but did not report swallowing problems. The patient was mobilized on day 3 with physiotherapy.

Despite antibiotic therapy the patient had persistent fever, raised inflammatory markers, and ongoing chest and back pain, prompting further investigation. On day 8 after injury, the patient underwent a chest Computed Tomography (CT) scan, which revealed thoracic esophageal perforation secondary to fourth thoracic vertebral fracture, complicated by pleural empyema and mediastinal abscess. There was a moderate amount of free posterior mediastinal gas anterior to the thoracic spine and on the right side of the mediastinum, with a rind of soft tissue but no visible fluid. Oblique fracture of the T4 vertebral body extending from anterosuperior to posteroinferior with $4 \mathrm{~mm}$ of retrolisthesis, no involvement of the pedicles or posterior elements, and underlying ankylosed spine with extensive syndesmophyte (Figure 


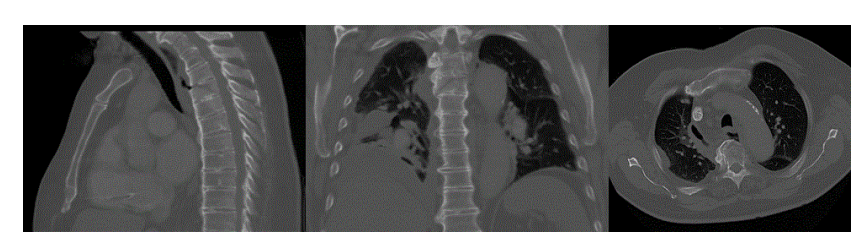

Figure 1: Sagittal, Coronal and Axial CT scans - Oblique fracture T4 vertebral body, free mediastinal gas. Posterior to esophagus at T4 level.

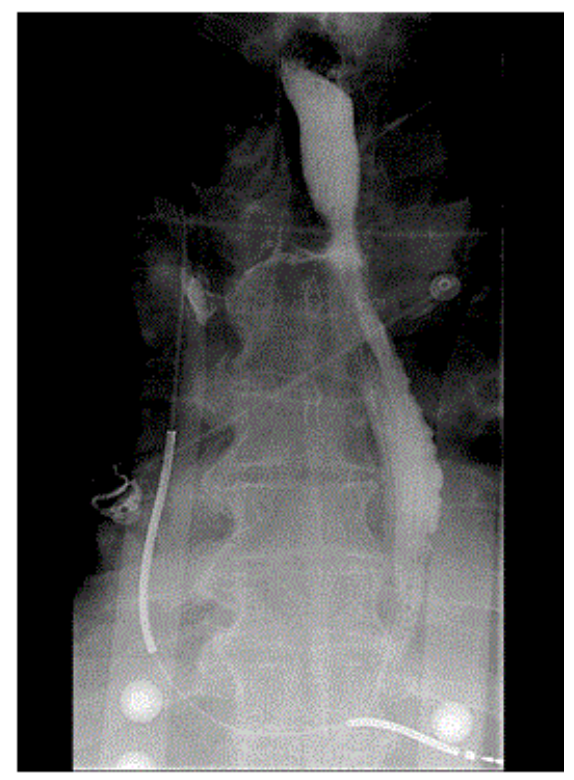

Figure 2: Gastrograffin swallow Esophagography. Contrast extravasation at the T4 level.
Page 80

1). In addition, there was evidence of right lung middle and lower lobe consolidation with pleural effusion. Diagnostic imaging with MRI was contraindicated due to the patient's AICD. Gastrograffin swallow contrast esophagography confirmed esophageal laceration and ongoing leak at the level of the T4 vertebral body, with active contrast extravasation from the esophagus to the right side of the mediastinum (Figure 2).

The esophageal perforation, sepsis, chest complications and thoracic spine fracture were successfully treated with non-surgical management. The Gastroenterologist advised conservative management for the traumatic esophageal laceration and stenting was not employed due to the delayed diagnosis and established infected pleural and mediastinal complications. Cardiothoracics instigated conservative management for the pleural empyema and mediastinal abscess, and the Infectious diseases unit directed intravenous antibiotic therapy. The patient was treated nil by mouth, with total parenteral nutrition, and followed with serial gastrograffin swallow studies. Non-surgical management was directed by Neurosurgery for the thoracic vertebral body fracture. This decision was made as the patient had already been mobilized, and follow-up imaging showed no change in fracture alignment, as well as the patient's significant Eqreserbidities ritise which precluded a general anesthetic in the prone position. Initial orthotic spinal brace fitting was contraindicated due to

The patient was nursed with spinal precautions and log roll pressure care, until the esophageal leak and chest complications had resolved. The patient was managed in the intensive care unit for 4 days, and then nursed in a single room on the general ward. At day 42 after injury, gastrograffin swallow study showed the esophageal laceration had resolved, with no evidence of extra-luminal contrast extravasation to suggest ongoing leak. A repeat chest CT scan revealed resolution of the chest collections/empyema and mediastinal gas, and stable configuration of the T4 vertebral fracture with evidence of early bone healing. Diet was restarted without complications. The esophageal laceration healed without further leak, and the patient tolerated oral intake without swallowing difficulties. The patient was mobilized in a Boston brace custom-made overlap "clam shell" design (anterior and posterior sections, side fastenings and shoulder straps), and discharged to a rehabilitation facility. The thoracic fracture remained stable on serial spine imaging and CT scan showed fracture union. The patient remained neurologically intact, and conservative non-surgical management resulted in complete recovery.

Table I: Cases of post-traumatic esophageal perforation after thoracic spine fracture; MA - Motorcycle Accident; MVA - Motor Vehicle Accident; F - Fall; AS - Ankylosed Spine; E - Esophagus; TS - Thoracic Spine; Ch - Chest; C - Conservative; S - Surgery.

\begin{tabular}{|c|c|c|c|c|c|c|}
\hline $\begin{array}{l}\text { CASE } \\
\text { (Reference) }\end{array}$ & LEVEL & $\begin{array}{l}\text { CONTRIBUTING } \\
\text { FACTORS }\end{array}$ & $\begin{array}{l}\text { DELAYED } \\
\text { DIAGNOSIS } \\
\text { [Time] }\end{array}$ & MANAGEMENT & NEUROLOGICALLY INTACT & SURVIVED \\
\hline $1(16)$ & $\mathrm{T} 3, \mathrm{~T} 4$ & MA & $\begin{array}{l}\text { Yes } \\
\text { [14 Days] }\end{array}$ & $\begin{array}{l}\mathrm{E}:[\mathrm{C}] \\
\text { TS: }[\mathrm{S}] \\
\text { Ch: }[\mathrm{S}]\end{array}$ & Yes & Yes \\
\hline $2(7)$ & $\mathrm{T} 3, \mathrm{~T} 4$ & MA & $\begin{array}{l}\text { Yes } \\
\text { [11 Days] }\end{array}$ & $\begin{array}{l}\mathrm{E}:[C] \\
\text { TS: }[C] \\
\text { Ch: }[C]\end{array}$ & Yes & No \\
\hline $3(17)$ & $\mathrm{T} 3, \mathrm{~T} 4$ & MA & No & $\begin{array}{l}\mathrm{E}:[\mathrm{S}] \\
\mathrm{TS}:[\mathrm{S}]\end{array}$ & No & Yes \\
\hline
\end{tabular}




\begin{tabular}{|c|c|c|c|c|c|c|}
\hline & & & & Ch: [S] & & \\
\hline $4(18)$ & $\mathrm{T} 3, \mathrm{~T} 4$ & MVA & $\begin{array}{l}\text { Yes } \\
\text { [6 Days] }\end{array}$ & $\begin{array}{l}\text { E: [S] } \\
\text { TS: [S] } \\
\text { Ch: [C] }\end{array}$ & Yes & Yes \\
\hline $5(19)$ & T2 & MVA & $\begin{array}{l}\text { Yes } \\
\text { [5 Months] }\end{array}$ & $\begin{array}{l}\text { E: [C] } \\
\text { TS: }[C] \\
\text { Ch: }[C]\end{array}$ & No & Yes \\
\hline $6(20)$ & $\mathrm{T} 3, \mathrm{~T} 4$ & MVA & No & $\begin{array}{l}\text { E: [S] } \\
\text { TS: [S] } \\
\text { Ch: [S] }\end{array}$ & No & Yes \\
\hline 7 (Current) & $\mathrm{T} 4$ & F, AS & $\begin{array}{l}\text { Yes } \\
\text { [8 Days] }\end{array}$ & $\begin{array}{l}\text { E: [C] } \\
\text { TS: }[C] \\
\text { Ch: }[C]\end{array}$ & Yes & Yes \\
\hline
\end{tabular}

\section{Discussion}

Esophageal perforation is rare and is associated with high morbidity and mortality $[1-3,6,8,21,22]$. It can be attributed to a number of etiologies, including spontaneous rupture, iatrogenic injury, blunt or penetrating trauma [2]. In 15 to $20 \%$ of esophageal perforations trauma is the cause, often due to penetrating neck or thorax injury, and more common with cervical spine trauma [10-14]. Blunt trauma can occur in deceleration injury, with raised intraluminal pressure resulting in esophageal wall tear.15 Forced neck hyperextension can cause cervical esophageal perforation, and shearing-distraction injuries can result in thoracic esophageal perforation [16]. Delayed diagnosis and treatment can be due to lack of obvious symptoms or signs masked by other injuries, and result in serious complications such as sepsis, pleural empyema and mediastinitis [7,23]. Presentation can include a range of symptoms, dysphagia, odynophagia, dyspnea, progressive sepsis, tachycardia, pyrexia, chest pain and surgical emphysema. Prompt diagnosis and management is important to prevent life threatening complications, with greater than $50 \%$ mortality rates reported for surgery more than 24 hours after esophageal perforation [7-9]. In certain cases, non-surgical management can be employed $[2,3,24]$.

In the largest comprehensive review to date of thoracic esophageal perforations there were no cases of thoracic spine fracture etiology [25]. There are only six reported cases of post-traumatic thoracic esophageal perforation due to thoracic spine fractures (Table 1) $[7,16-20]$. We present the first case not associated with a road traffic accident, in a patient with an ankylosed spine, with injury sustained after a low velocity fall. This is the only reported case of post-traumatic thoracic esophageal perforation secondary to thoracic T4 vertebral fracture, in a patient with an ankylosed spine that survived neurologically intact after successful conservative management.

The spinal column is located close to the esophagus between C5 and T4 [7]. with the physiologically narrow esophageal region close to the third and fourth thoracic vertebrae [8]. With hyperextension injury of the spine, forces can be transferred from the spine to the esophagus is this area, resulting in esophagus perforation [7]. Penetration of the esophagus can result from a spinal fracture fragment [16]. Contrast esophagography is the gold standard for localization and diagnosis of esophageal perforation [2,3,15]. Extra-luminal peri-esophageal air is reported as the most useful finding on chest CT [26]. Chest CT can also identify thickening of the esophageal wall, esophageal distortion or displacement at the cervico-thoracic junction, and para-esophageal manifestations such as mediastinal abscess, and pleural collections or effusions [2,26-28].

The presented case highlights the importance of vigilance in all trauma cases involving patients with ankylosing spinal enthesopathy, even after a low velocity mechanism. This report also serves to increase clinician awareness of possible thoracic esophageal injury following upper thoracic spine fracture. Ankylosing Spondilitis (AS), also known as Marie-Strümpell disease, is a seronegative arthropathy, with peak incidence age 17 to 35 years. The primary skeletal site involved is the spine, usually progressing rostrally from the sacroiliac joints and lumbar spine. The spinal enthesopathy produces the "bamboo spine", square-appearing osteoperotic vertebral bodies with bridging syndesmophytes due to ossified ligaments and calcified intervertebral discs. The rigid spine of AS when fractured acts as a long lever, and fracture may occur following minimal trauma, these fractures are typically very unstable and usually required surgical fixation. In this case it was fortunate that the fracture was stable and able to withstand early mobilization.

Esophageal injuries can be managed with conservative management or operative intervention, with supportive measures to control sepsis and provide adequate nutrition [2,3]. Surgical options may include primary closure, drainage, diversion, or esophagectomy [2,3]. In selected cases, esophageal perforations can heal with non-operative management consisting of broad-spectrum antibiotics, strict oral hygiene, nil orally and total parental nutrition $[2,3]$. The complex decision on treatment for the esophageal perforation depends on the patient's clinical circumstances. Treatment selection should be based on patient condition and performance status, timing of diagnosis, resources available, esophageal pathology, and presence/absence of complications, local phlegmon, and/or sepsis [25]. Prompt diagnosis and management of esophageal perforation is of paramount importance to attempt to avoid serious complications. Our case report 
demonstrates that good outcome can be achieved with non-operative management.

\section{References}

1. Gupta NM, Kaman L (2004) Personal management of 57 consecutive patients with esophageal perforation. Am J Surg 187: 58-63.

2. Wu JT, Mattox KL, Wall MJ Jr (2007) Esophageal perforations: new perspectives and treatment paradigms. J Trauma 63: 1173-1184.

3. Brinster CJ, Singhal S, Lee L, Marshall MB, Kaiser LR, et al. (2004) Evolving options in the management of esophageal perforation. Ann Thorac Surg 77: 1475-1483.

4. Kiernan PD, Sheridan MJ, Elster E, Rhee J, Collazo L, et al. (2003) Thoracic esophageal perforations. South Med J 96: 158-163.

5. Zumbro GL, Anstadt MP, Mawulawde K, Bhimji S, Paliotta MA, et al. (2002) Surgical management of esophageal perforation: role of esophageal conservation in delayed perforation. Am Surg 68: 36-40.

6. Cohn HE, Hubbard A, Patton G (1989) Management of esophageal injuries. Ann Thorac Surg 48: 309-314.

7. Nakai S, Yoshizawa H, Kobayashi S, Miyachi M (1998) Esophageal injury secondary to thoracic spinal trauma: the need for early diagnosis and aggressive surgical treatment. J Trauma 44: 1086-1089.

8. Bladergroen MR, Lowe JE, Postlethwait RW (1986) Diagnosis and recommended management of esophageal perforation and rupture. Ann Thorac Surg 42: 235-239.

9. Brewer LA, Carter R, Mulder GA, Stiles QR (1986) Options in the management of perforations of the esophagus. Am J Surg 152: 62-69.

10. Stringer WL, Kelly DL Jr, Johnston FR, Holliday RH (1980) Hyperextension injury of the cervical spine with esophageal perforation. Case report. J Neurosurg 53: 541-543.

11. Pollock RA, Purvis JM, Apple DF Jr, Murray HH (1981) Esophageal and hypopharyngeal injuries in patients with cervical spine trauma. Ann Otol Rhinol Laryngol 90: 323-327.

12. Agha FP, Raji MR (1982) Oesophageal perforation with fracture dislocation of cervical spine due to hyperextension injury. Br J Radiol 55: 369-372.

13. Tomaszek DE, Rosner MJ (1984) Occult esophageal perforation associated with cervical spine fracture. Neurosurgery 14: 492-494.

14. Reddin A, Mirvis SE, Diaconis JN (1987) Rupture of the cervical esophagus and trachea associated with cervical spine fracture. J Trauma 27: 564-566.
15. Beal SL, Pottmeyer EW, Spisso JM (1988) Esophageal perforation following external blunt trauma. J Trauma 28: 1425-1432.

16. Brouwers MA, Veldhuis EF, Zimmerman KW (1997) Fracture of the thoracic spine with paralysis and esophageal perforation. Eur Spine J 6: 211-213.

17. Chen SH, Huang TJ, Chen YJ, Liu HP, Hsu RW (2002) Flexiondistraction injury of the upper thoracic spine associated with tracheoesophageal perforation. A case report. J Bone Joint Surg Am 84-84A: 1028-31.

18. Tjardes T, Wafaizadeh A, Steinhausen E, Krakamp B, Bouillon B (2009) Extension injury of the thoracic spine with rupture of the oesophagus and successful conservative therapy of concomitant mediastinitis. Eur Spine J 18 Suppl 2: 240-244.

19. Lee DH, Kim NH, Hwang CJ, Lee CS, Kim YT, et al. (2011) Neglected esophageal perforation after upper thoracic vertebral fracture. Spine J 11: 1146-1151.

20. Maroney MJ, Mirvis SE, Shanmuganathan K (1996) Esophageal occlusion caused by thoracic spine fracture or dislocation: CT diagnosis. AJR Am J Roentgenol 167: 714-715.

21. Henderson E, Echavé V, Lalancette M, Langlois G (2007) Esophageal perforation in closed neck trauma. Can J Surg 50: E5-6.

22. Strauss DC, Tandon R, Mason RC (2007) Distal thoracic oesophageal perforation secondary to blunt trauma: case report. World J Emerg Surg 2: 8 .

23. Flynn AE, Verrier ED, Way LW, Thomas AN, Pellegrini CA (1989) Esophageal perforation. Arch Surg 124: 1211-1214.

24. Vogel SB, Rout WR, Martin TD, Abbitt PL (2005) Esophageal perforation in adults: aggressive, conservative treatment lowers morbidity and mortality. Ann Surg 241: 1016-1021 .

25. Kiernan PD, Khandhar SJ, Fortes DL, Sheridan MJ, Hetrick V (2010) Thoracic esophageal perforations. Am Surg 76: 1355-1362.

26. White CS, Templeton PA, Attar S (1993) Esophageal perforation: CT findings. AJR Am J Roentgenol 160: 767-770.

27. Fadoo F, Ruiz DE, Dawn SK, Webb WR, Gotway MB (2004) Helical CT esophagography for the evaluation of suspected esophageal perforation or rupture. AJR Am J Roentgenol 182: 1177-1179.

28. Young CA, Menias CO, Bhalla S, Prasad SR (2008) CT features of esophageal emergencies. Radiographics 28: 1541-1553. 